\title{
Domination and the (Instrumental) Case for Free Time*
}

\author{
DESIREE LIM \\ The McCoy Center for Ethics, Stanford University
}

\begin{abstract}
This paper examines the case for fair shares of free time from a civic, or neo-republican perspective. I claim that, unlike liberal egalitarians like Julie Rose, who can make a straightforward case for free time, republicans' theoretical commitments make it more appropriate for them to throw their weight behind a portion of time specially allotted for political activity. However, as I will show, republicans have strong instrumental reasons to endorse fair shares of free time for all citizens. First, focusing on the idea of non-domination, I outline the typical preoccupations of republicanism that I believe have direct implications for how they ought to treat the topic of free time. Next, focusing on the case of domination in the workplace, I claim that fending off the threat of domination requires a substantial amount of time. Chiefly, workers need time to effectively participate in processes of justification and contestation, in order to uphold sturdy checking mechanisms that can protect them against domination. As a consequence, setting aside a window of time specially devoted to political activities, rather than free time in itself, is more consistent with the republican project. Nevertheless, in the final section, I conclude that "free time" would be instrumentally necessary on the republican picture. Fair shares of free time are a preferable means to achieving conditions of nondomination than compulsory time for political activity, for practical and principled reasons.
\end{abstract}

Keywords: republicanism; domination; freedom; workplace democracy; free time

\footnotetext{
* I am indebted to my colleagues at the McCoy Center for Ethics in Society, Tom Parr, Philip Pettit, Alex Gourevitch, an anonymous reviewer, and the LEAP editors for their valuable comments on an earlier draft of this paper. I also thank Grant Macdonald for helpful information on unionization efforts amongst student workers.
} 


\section{INTRODUCTION}

Julie Rose has argued persuasively that liberal egalitarians ought to embrace free time as a distinct object of egalitarian concern. Specifically, she contends that free time, defined here as time that can be devoted to one's chosen ends at one's discretion, as opposed to time constrained by necessary activities, is a resource that citizens are entitled to a fair share of (Rose 2016: 39). ${ }^{1}$ This is because free time is a resource that is "generally required for the pursuit of one's chosen ends, whatever those may be", as well as "generally required to exercise one's formal liberties and opportunities" (Rose 2016: 67). Rose's book is a crucial intervention into the neglect of free time despite its political and philosophical significance. My contribution to the symposium further advances this goal by examining the case for a fair share of free time from a civic, or neo-republican perspective. ${ }^{2}$ I claim that, unlike liberal egalitarians like Rose, who can make a straightforward case for free time, republicans' theoretical commitments make it more appropriate for them to throw their weight behind a portion of time specially allotted for political activity. However, as I will show, republicans have strong instrumental reasons to endorse fair shares of free time for all citizens.

In Section 2, focusing on the idea of non-domination, I outline the typical preoccupations of republicanism that I believe have direct implications for how they ought to treat the topic of free time. In Section 3, focusing on the case of domination in the workplace, I claim that fending off the threat of domination requires a substantial amount of time. Chiefly, workers need time to effectively participate in processes of justification and contestation, in order to uphold sturdy checking mechanisms that can protect them against domination. As a consequence, setting aside a window of time specially devoted to political activities, rather than free time in itself, is more consistent with the republican project. Nevertheless, in the final section, I conclude that "free time" would be instrumentally necessary on the republican picture. Fair

1 We should leave open the possibility that at least some non-citizens might be entitled to time-related rights, especially those who participate in the host country's workforce. However, this discussion, as Rose's does, will focus only on citizens.

2 Here, I don't claim that republicanism is the theory of justice we ought to prefer. Rather, I am interested in seeing how much of Rose's argument for fair shares of free time can be preserved in a different political framework, as well as calling attention to the temporal dimension within republicanism. Neither do I claim that the central argument I make for free time is the only republican path that can be taken to this destination. For example, the labor republicans discussed by Alex Gourevitch in From Slavery to the Cooperative Commonwealth (Cambridge: Cambridge University Press, 2014) have contended that each person needed adequate time for political engagement and personal development. My intention is simply to highlight one of the core preoccupations of contemporary civic/neo-republicans and show how this might lead to a distinctive instrumental argument for fair shares of free time. 
shares of free time are a preferable means to achieving conditions of nondomination than compulsory time for political activity, for practical and principled reasons.

\section{CIVIC/NEO-REPUBLICANISM AND NON-DOMINATION}

\subsection{The definition of republicanism}

Characteristically, republicans believe that the existence of domination is what makes the exercise of power unjust. I will avoid commenting on disagreements between various strains of civic republicanism, instead only seeking to outline what I take to be the fundamental tenets of a republican theory. In line with Philip Pettit's influential account (1997), there are three basic aspects to any dominating relationship. Someone has dominating power over another to the degree that they have the capacity to interfere, on an arbitrary basis, in particular choices that the other is able to exercise (Pettit 1997: 52-4). Interference may encompass a wide range of possible behaviors, including coercion of their physical body or will, as well as manipulation, which takes the form of agendafixing, deceptively shaping people's beliefs or desires, or rigging the consequences of their actions (Pettit 1997: 52). It worsens agents' situations by altering their range of options, the predicted payoffs assigned to those options, or by establishing control over which outcomes will result from which options (Pettit 1997: 53). Importantly, it is not necessary that the dominating agent actually interferes with the dominated party; in fact, the person who enjoys that power need not even be inclined towards interference (ibid). The emphasis, instead, is on their effective capacity to interfere, which leads the power-victim to live at the mercy of the power-bearer (Lovett 2013: 98). In addition, exit costs on the part of the power-victim, which Frank Lovett terms "dependency", play a role in determining a dominating relationship's level of intensity. As he puts it, "the greater the dependency of subject persons or groups, the more severe their domination will be, other things being equal" (Lovett 2013: 50). Suppose that leaving a dominating social relationship would worsen someone's prospects, and that undertaking the move itself would impose further costs and risks (ibid). The higher the exit costs for the dominated party, the more leeway dominating agents have in treating her poorly, as they can do so with the knowledge that she is not likely to leave the relationship.

For my present purposes, I want to focus more closely on what it means for interference to be arbitrary. I take interference to be arbitrary when it 
is only subject to the discretion or goodwill of the power-holder, and is not forced to track the interests of those who are interfered with (Pettit 1997: 55). ${ }^{3}$ Of course, power-holders may freely cater to the interests of those they interfere with, like in the case of a benevolent dictator who cares deeply about the well-being of her subjects. Nevertheless, the benevolent dictator still dominates insofar as her interference is unchecked, unconstrained, or unaccountable (ibid). In what ways, then, can power-holders be "forced" to track the interests of their powersubjects? Checking mechanisms - institutional arrangements that place limits on how power-holders may use their power - may perform these three functions:

a. Justification: ensuring that power is justified to its subjects, whether by appeal to norms of public reason, and/or through their participation in democratic processes; ${ }^{4}$

b. Contestation: ensuring that subjects of the power are able to protest if their interests fail to be met;

c. Retribution: ensuring that power-holders are appropriately punished if they do not track power-subjects' interests. (Benton 2010: 408).

As the next section will reveal, the need for robust checking mechanisms, especially those pertaining to justification and contestation, is of special importance to the relationship between republicanism and time.

To sum up, for republicans, society must aim for a distribution of rights, goods, and resources that secure each individual's status as safe from domination. One necessary condition for non-domination, which I continue to focus on in the remainder of this article, is the existence of sturdy checking mechanisms that force power-wielding agents to track the interests of their power-subjects.

3 I leave open how "interests" ought to be determined.

4 For Benton, justification refers to governments having to give citizens reasons for their decisions, as well as being forced to respond to citizens' interests through the democratic process. However, one concern is that she provides an incomplete account of the role of democratic procedures. Other than forcing reason-giving and responsiveness from those in power (termed the "output-based view" by Bellamy (2008)), democracy also encompasses participation that render decisions non-arbitrary (termed the "input-based view"). On the "input-based view", it is not the content of the decisions made that renders power non-arbitrary, but my having equal status in public decision-making processes (Bellamy 2008: 164). While drawing on her categories, I depart from Benton by interpreting justification in the broad sense, taking it to include democratic justification through coauthorship. On my view, democracy helps justify state power through compelling it to enact responsive policies, and the fact I am able to play a co-authoring role through participation. 


\section{TIME AND NON-DOMINATION}

I will now establish the conceptual link between time and non-domination. Republicans, I believe, can make a distinct argument for free time that is nevertheless complementary to the liberal egalitarian one. To briefly visit the latter, I take it that liberal egalitarianism's two central commitments are to individual freedom of choice, as well as some degree of equality in the distribution of society's benefits. On this account, what will make the exercise of political power unjust is if citizens are unable to meaningfully exercise their individual freedom of choice, or because the distribution of society's benefits is unequal to the extent that some citizens are significantly less able to utilize those liberties and opportunities. Consequently, it is not difficult to see why a fair distribution of free time ought to be championed by the liberal egalitarian. If the distribution of free time is inegalitarian, with some people enjoying a much larger amount of time that can be devoted to their chosen ends at their discretion than others, some citizens would be far less able, or even unable, to meaningfully pursue their projects and commitments.

However, looking to non-domination reveals a different path from which we might reach a similar destination. I make the following argument in two stages. In the first stage, I argue that there is an important temporal dimension to republicanism. As emphasized in the previous section, republicans greatly value the presence of checking mechanisms that ensure that power-wielders are forced to track the relevant interests of power-subjects. Given that successfully establishing checking mechanisms and keeping them in place is often very time-consuming, it is important that power-subjects have enough time to do so. To bring out the significance of time for republicans, I concentrate on the concrete case of nondomination in the workplace. Chiefly, workers need time to establish or participate in crucial processes of justification and contestation that protect them against workplace domination. I expand on these points below. The second stage, which argues that free time - and not just time in itself - may be instrumentally necessary for us to have sufficient time for political activity, will be fully developed in section 4 .

Before I proceed, a note about how we ought to envision the relationship between my argument and the liberal egalitarian one is in order. As I have hinted, I view the republican case for free time as a friendly companion to the liberal egalitarian one. It does not challenge the premises of the liberal egalitarian argument, but simply brings out another important political function of free time. Assuming that relations of domination are a quintessential type of social inequality, where the dominated suffer an 
inferior public status, it helps to bridge a key connection between free time and social equality - a connection that Rose's account does not fully investigate. Combined, the two arguments help us build a strengthened case for fair shares of free time.

\subsection{Domination in the workplace}

The extent of domination that can be found in present-day workplaces should not be underestimated. Elizabeth Anderson has made an explicit comparison between workplaces and authoritarian governments. For her, the workplace is akin to a private government where everyone must obey an assigned superior who is "unaccountable to those they order around", as they are "neither elected nor removable by their inferiors", and who issues orders that "may be arbitrary and can change at any time, without prior notice or opportunity to appeal" (Anderson 2015: 94). Similarly, as Alex Gourevitch puts it,

"...the typical workplace is a site of domination not self-government, of arbitrary power not democratic control. Workers are subject to a panoply of rules, directives, orders, commands, whims, caprices, and impositions over which they have no legal control and that they have limited capacity to resist" (Gourevitch 2016: 17-8).

While workplace domination may come in diverse guises, I will describe two forms that Gourevitch has helpfully identified: personal and structural domination. In line with the definition sketched out in the previous section, these forms of domination do not hinge on employers possessing malicious intentions, or even their actual interference with workers. It is enough for them to possess the capacity to do so, in virtue of current systems of employment that are routinely taken for granted.

As a starting point, workers suffer personal domination when they are subject to the arbitrary authority of bosses whom they are conventionally expected to obey (Gourevitch 2015: 316). Employers have frequently been judged to be within their rights when subjecting workers to unreasonably harsh working conditions, or flat-out demeaning and humiliating treatment. These include being forced to work in extreme heat or physically hazardous but not illegal conditions, being forced to wear diapers rather than go to the bathroom, being refused lunch breaks, or being forced to take random drug tests (ibid). Importantly, these exercises of power often go above and beyond what has been explicitly spelt out in contracts, and thus what has been assented to by the employee at the outset. This is because employers have the authority to specify underdetermined terms in work contracts, which are necessarily vague or incomplete (Gourevitch 
2013: 607). For instance, despite the potential for wide-ranging disputes over conditions of employment, including questions about whether the political views or social media postings of employees are a reasonable basis for being fired, these decisions are largely controlled by employers (ibid). As this example reveals, vagueness or incompleteness paves the way for employers' control to creep into employees' off-hour lives. As Anderson observes, most believe that they cannot be fired for their off-hours Facebook postings, or for backing a political candidate their boss opposes, but only half of American workers enjoy even partial protection of their off-duty speech from employer retaliation (Anderson 2015: 95-6). In these ways, personal domination by employers goes beyond poor treatment during work hours: it involves the capacity to exercise insidious power even over intimate aspects of workers' lives.

On top of personal domination, workers also experience structural domination, which rises out of how they are forced to sell their labor-power in the absence of reasonable alternatives to wage labor (Gourevitch 2015: 313). Many societies are structured such that some group of owners privately controls all of society's productive assets, and non-owners are forced by the legally protected unequal distribution of productive assets to sell their labor to some employer or other (Gourevitch 2013: 602). Because labor is forced, under the current structure of property-ownership, employers have the capacity to set arbitrary terms and conditions for job positions, with the knowledge that they will continue to be filled. Many end up working "longer hours, at lower pay, under worse conditions than they would otherwise accept" not because they want to, but because they must (Gourevitch 2015: 314). Echoing Lovett's contention that dependency makes domination more intense, structural domination heightens personal domination because it makes workers dependent on employers for a living wage. In the absence of reasonable alternatives to selling one's labor, there are onerous exit costs to leaving the job market. This dependency may be exploited by employers who force employees to work under harsh or punishing conditions precisely because they know the workers do not have adequate exit options. Furthermore, as Gourevitch notes, even if employers do not intentionally seek to take advantage of workers, exploitation is implicit in their economic decisions about firing, hiring, wages, and hours that presume a steady supply of economicallydependent labor. Again, employers can fire a worker who challenges their authority, knowing they can most likely be easily replaced. In short, the exiting imposes asymmetrical costs on workers and employers. This has the effect of forcing workers to put up with bad jobs, while permitting employers to get away with exploitation and ill-treatment. 
To be clear, the argument is not that all workers are equally dominated. Of course, there is a wide spectrum of domination across different lines of work, with some privileged classes of employees enjoying relatively low levels of personal and structural domination (compare a factory worker to a tenured university professor with multiple job offers). The extent of workplace domination that we experience may also be influenced by our individual career choices: if, for example, I chose to be a professional football player whose employers are considerably more dominating than if I had chosen the alternative of being a tenured university professor. ${ }^{5}$ However, because of the underlying structure of property-ownership, all workers are dominated to some extent, and the privileged class of workers who experience trivial levels of domination is relatively narrow. Furthermore, I submit that there is a comparably narrow class of socially privileged people who have voluntarily chosen a more dominating job over a less dominating one, often because of other valuable payoffs (like fame and fortune in the football player case). More often than not, workers do not have access to less dominating alternatives that would not also be accompanied by significant exit costs, and this is the group that I take theorists like Anderson and Gourevitch to be interested in. Finally, it is worth noting that my voluntarily choosing a more dominating job over a less dominating one does not necessarily neutralize the wrong of domination. To see this point, suppose that I voluntarily choose to marry Adam over Ben with the knowledge that I am more likely to be dominated in my relationship with Adam, who has a rather controlling personality. Yet it would be misguided to say that my freely choosing Adam over Ben makes Adam's dominating behavior over me morally acceptable.

\subsection{Domination and checking mechanisms}

How ought we respond to these instances of personal and structural domination? Here, I want to focus on how checking mechanisms can help to reduce employers' capacity for arbitrary interference. In 2.1, I introduced three types of checking mechanisms that force power-holders to track the interests of power-subjects: those that enable justification, contestation, and retribution. I now consider how these checking mechanisms bear on workplace domination. Specifically, I will explore how processes of contestation and justification that directly involve workers can be

5 I thank Tom Parr for this example, and for pressing me on these points. 
implemented to keep employers' arbitrary power in check. ${ }^{6}$

First, workplace decisions should be made robustly contestable by workers. In order to be emancipated from the relationships of domination they experience in the workplace, workers ought to organize themselves into political organizations and industrial unions, thus transforming the social and economic order (Gourevitch 2016: 25). ${ }^{7}$ This is because the formation of such organizations and unions would allow workers to robustly contest situations where their interests fail to be met through strengthening their collective bargaining power, thus empowering them to challenge arbitrarily-made decisions. If employees found themselves faced with unreasonable or humiliating demands from the employer, they could dispute these with the union's backing. Being a trade union or staff association member has been shown to increase the odds of a problem at work being resolved satisfactorily (Compa 2004: 5). In addition, while being part of a union in itself does not give workers a direct say in determining the terms and conditions of employment, unionized workers typically enjoy significantly more favorable working conditions than non-unionized workers. ${ }^{8}$

Workplace decisions should also be justified to workers. Notably, it has been suggested that a right to justification regarding the conditions of one's labor should be understood as the extension of the moral right to selfdetermination; "we have a right to demand and be given good reasons when deliberating over matters that affect us in important ways" (Borman 2017: 82). One way the right to justification can be satisfied is for employees to participate in a system of co-determination, where they share control of an economic enterprise with providers of capital, such as through work committees and employee representation on boards of directors (Hsieh 2008: 92). In order to ensure that employees are treated as fellow deliberators, instead of silent parties who passively wait to have rules or

$6 \quad$ I do not claim that implementing such mechanisms would be sufficient to protect workers from domination. For example, they may need to be accompanied by measures that improve workers' exit options, such as more generous welfare payments or a universal basic income. However, I don't think that improving exit options on their own would be sufficient, as they do not address the domination suffered by workers who choose to remain employed. For this reason, the importance of contestation and justification remains.

$7 \quad$ It is important to note that, while Gourevitch believes that transforming the order requires workers to organize themselves in unions, it is also necessary for structural domination to be addressed at a deeper level by cooperatively organizing the means of production. I don't disagree with the importance of changing the structure of employment, but here I choose to focus on what can be done to lessen domination within existing structures.

8 See http://www.epi.org/publication/briefingpapers bpl43/ for some statistics on this issue. 
decisions enacted upon them, they should be guaranteed the right to participate in determining the policies that affect them, as well as play a role in governing the enterprise more generally (ibid). Concretely, participation in decision-making would give employees the ability to determine the terms and conditions of their employment and the wider organization of their work, so that these do not lean entirely on the employer's authority.

Of course, this is not to place all of the burden of protecting against domination on the workers themselves and detract from states' responsibilities to their citizens. In fact, workers' ability to form trade unions is heavily dependent on the existence of state-enforced labor laws that protect their freedom of association. I believe it is consistent, however, with the spirit of republicanism to pay significant attention to political action on the part of private citizens.

\subsection{Time and checking mechanisms}

Now that I have identified two commonplace forms of workplace domination, as well as suggested two measures that could be used to address them, I will clarify the links between these and the subject of time. Chiefly, I contend that the establishment and maintenance of those checking mechanisms would require a substantial amount of time. If workers lack adequate time-resources to participate in these activities, as I believe many currently do, workplace domination would remain seriously unaddressed. Broadly speaking, individuals must possess adequate timeresources in order to effectively justify and contest the interference of power-holders, therefore protecting themselves from domination.

First of all, the formation of political organizations and industrial unions tends to require many onerous steps. For example, employees wanting to form industrial unions would need to canvass support from other workers, or allies outside of the workplace; they would have to find ways of making decisions about who should lead and motivate the union; they would have to tread through red tape for the union to be approved by government agencies. It is obvious that going through the appropriate motions would be immensely time-consuming. Even if employees chose instead to join pre-existing unions, they would still require time to decide which union to join, as well as obtain the union's approval to represent them, and communicate the issues that they wish to negotiate. In addition, in order for workers to successfully contest retributive decisions by employers or managers, they would need to know their rights and understand how exactly these have been violated. Again, in order to clearly understand what we are entitled to, and how it may apply in particular 
situations, we would require time to educate ourselves on these matters. In some cases, it would involve having to seek legal assistance; locating and consulting an appropriate authority on the matter would, no doubt, require even more time.

Participating in workplace decision-making might be comparably time-consuming for workers. Suppose that a team of workers is allowed to decide on their own rate of compensation, or have a say in an important decision that will determine their company's future path, as opposed to these decisions being made autocratically by higher-ups. It is very unlikely that all the workers would immediately agree with one another about how to act; instead, disagreement would probably have to be teased out, and compromise or consensus eventually reached, through a series of deliberation. (Tellingly, the hypothesis that more democracy in the workplace mean slowing down decision-making, hence harming productivity or efficiency, has often been used against advocates.) Furthermore, I assume here that the people involved in decision-making are not themselves responding arbitrarily or idiosyncratically, but in a responsible and well-grounded way. Making well-informed decisions - for example, when deciding on a fair rate of compensation - would require the employees to perform research on what people in related fields are earning, or perhaps to come up with a justification for why persons performing a particular task merit more compensation than others performing what appears to be a similar one. Simply put, research and reflection for collective decision-making requires time.

I have tried to show why the resource of time is crucial to the establishment and maintenance of checking mechanisms in the workplace - mechanisms that are necessary to stave off the threat of domination. Before concluding this section, I note three final points on time and its relation to non-domination. Importantly, given the history of employers' hostility to unionization and workplace democracy, it seems that introducing the checking mechanisms described above, in the first place, may require concerted effort and struggle from workers - suggesting that even more time may be necessary for practical implementation. The appropriate time-scale here is years, not months, with no guarantee of success. Take, for example, the ongoing attempts of graduate students in the US to obtain the right to unionize and the massive obstacles enacted by universities. Efforts have been blocked, despite students voting to join unions certified by the National Labor Relations Board (NLRB), by various universities on the grounds that the students should not be considered employees (Semuels 2017). A number of universities even hired a law firm known for their formidable powers against workers to block graduate 
students from organizing, signaling that they were prepared to spend years in court on the endeavor (Jordan 2017). The ongoing challenges graduate students face to successful unionization are likely to intensify given Donald Trump's presidency, under which they expect the NLRB's recognition of graduate students as employees to be reversed (Rivin-Nadler 2017). As this case demonstrates, workers' striving for sufficient contestation and justification in the workplace can feel like fighting a losing battle - to wit, a very time-consuming one.

Secondly, while the core argument I have given is very different in essence from Rose's, it dovetails with hers with respect to temporal coordination. Rose argues insightfully that exercising one's freedom of association does not only generally require the resource of free time, but also free time that is "shared with one's fellow associates" (Rose 2016: 93). This is because the central exercises of freedom of association, such as sharing a meal with one's family, marching in a rally with one's political co-partisans, or sharing religious services with one's fellow believers, involve engaging in the pursuit at the same time as others (Rose 2016: 94). Therefore, citizens must have reasonable access to shared free time in order to exercise their freedom of association. Similarly, to a large extent, workers need shared time to perform contestory and justificatory activities together. Certainly, an individual can learn about the full extent of their employment rights, or launch a dispute against the employer on their own. But there is an important collective aspect to political organization and deliberation.

While I have chosen to focus on a smaller-scale case to bring out the central role of time in addressing specific forms of domination, the above arguments are meant to extend to political activity and the republican duties of citizens writ large. The kind of political engagement that enables political institutions to be effectively justified or contested is inherently time-consuming. Citizens need time to vote, run for office, or educate themselves on political institutions and political life more generally. For example, voting - the most basic form of political participation - often requires citizens to head to a particular location and stand in line for their turn to vote, which can be rather-time consuming. U. S. federal law does not require employers to give their staff time off to vote, and while a number of states have instituted their own laws on the matter, with some allowing up to three hours off to vote, not all states require that employees be remunerated for that time off. Coupled with other competing factors like caregiving duties, and the negative impact that losing even a few hours' wages can have, it is no surprise that many people are unable to set aside the time to vote, or find themselves having to leave polling stations because they cannot afford to continue waiting, thus contributing to voter 
suppression. It is in this way that citizens need time to be able to protect themselves against domination. Without sufficient time for citizens to participate in political activities designed to justify or contest power, state power cannot be properly kept 'in check'.

To conclude this section, on the republican account, possessing sufficient time-resources to engage in the justification and contestation of power is necessary for persons to protect themselves from domination. This is markedly different in tone from the liberal egalitarian picture, where time is deemed necessary for exercising our basic rights and opportunities, as well as pursuing the ends and projects we find valuable

\section{4. 'FREE’ VERSUS ‘SUFFICIENT’ TIME?}

So far, I have talked a lot about 'time', but not free time specifically. I attend to this in the final section by arguing that, unlike liberal egalitarians, republicans cannot make a case for the importance of the fair distribution of free time as a resource in itself. At most, they can make an instrumental argument for the fair distribution of free time, as ensuring fair shares of free time may be the best means of encouraging political engagement and the development of civic virtue, in comparison to the alternative. I explain why below.

\subsection{The instrumental necessity of free time}

Previously, I argued that many activities with a quintessentially republican flavor - and more particularly, those necessary for processes of justification and contestation - are inherently time-consuming, and that people need time to participate in them. However, this does not establish an argument for fair shares of free time. It simply shows that citizens need a sufficient portion of time to engage in political activity, and does not say anything about their claims to time for pursuits of their own choosing. In contrast, Rose's account does not specify what people ought to be doing with their free time beyond pursuing their chosen ends or exercising their formal liberties and opportunities. We can use our free time to be activists, surfers, or couch potatoes without judgment, so to speak. In other words, it is the liberal emphasis on the freedom to do whatever one wants with the allotted time that makes it "free". Without this, republicans cannot make a case for the entitlement to fair shares of free time, as opposed to sufficient time for political engagement.

Keeping this in mind, what kind of time-related policies ought republicans to endorse? One initial suggestion would be for the state to partition off a 
certain amount of time to be used exclusively for republican activities. For example, very crudely, citizens could be allocated five hours a week that would be compulsorily dedicated to some form of civic engagement. Yet this looks very unattractive, and unlikely to be endorsed by any present-day republican, as enforcement would be deeply problematic. How, exactly, would the state ensure that citizens would use the allotted time for political purposes alone? To start with, a high level of surveillance and intrusion into citizens' privacy would be required for states to police citizens' time-usage. In practice, the policy might end up licensing more domination on the part of the state; it equips the state with an excuse to monitor and control citizens' activity, enhancing its capacity to interfere with their choices on an arbitrary basis, and hence running counter to the policy's purported ends. It also seems that unpalatably coercive measures would have to be employed in order to deter citizens from misusing their time-share, such as penalizing them if they are caught using the time for some other activity.

Here, it might be objected that at least some republicans have endorsed coercive measures to ensure political participation, the case in point being mandatory voting, where citizens pay a financial penalty for failing to vote. Why, then, shy away from time for compulsory political activity? Yet mandatory voting would not involve the same level of intrusiveness, as citizens are penalized on the basis of records indicating that they failed to vote, rather than having their individual time closely monitored by the state. Nor is it as demanding, as citizens are penalized for a one-time failure to act, rather than for the failure to regularly engage in republican activities, which would plausibly lead to repeated fines for many people who are tired, distracted, disillusioned, or simply disinterested in politics. Furthermore, it might disproportionately impact less well-off citizens who are already less likely to participate in politics, yet for whom monetary fines would be more detrimental.

While intrusiveness and demandingness are, on their own, principled reasons against enforcing time-periods of compulsory political activity, such time-periods would arguably be counterproductive to the cultivation of authentic civic virtue. Being forced into regular political engagement would most likely turn it into a tiresome chore, draining the activity of any meaning or significance. Worse still, being punished for failing to do so would almost certainly create resentment and even more disillusionment with the practice of politics, rather than feelings of empowerment.

A second possible policy would be conditional time for political activity. That is, instead of giving all citizens a period of time they must dedicate to political activity, only those who are active members of political groups would be given time to participate in it. For example, the state might legally 
require corporations to give employees who are union members a certain amount of time off from work. This alternative policy avoids some of the worries I have outlined about compulsory time for political activity. It does not force the cultivation of civic virtue, but provides encouragement and support to those who have authentically chosen to be civically engaged. Furthermore, while it seems rather unlikely that anyone would go to the lengths of creating a bogus political organization just so they could use the allotted time for non-political pursuits like surfing or video games, imposing penalties on bogus organizations seems far less problematic than penalizing individuals for how they choose to use their time. For one, enforcing those penalties would not require violating the privacy of individuals; political organizations do not have an analogous right to privacy. Secondly, members of bogus political organizations are exploiting the system by engaging in deceit. It seems fair for deceitful behavior to be punished, rather than the mere lack of desire for political participation.

Unfortunately, conditional time also suffers from a fatal flaw. Namely, it adopts a very narrow view of what political participation is. Political engagement today encompasses a wide variety of activities, including marching in a street protest; writing petitions; creating art; or even posting on social media like Twitter and Facebook. But none of these forms of engagement involve formal membership that we can submit as proof of our participation. Only giving time to members of political organizations would deprive others of time for valuable political activities that do not hinge on membership. Worse still, states would be able to make value judgments about what is a valuable or worthwhile political activity that is worth supporting. This could risk disadvantaging those who participate in activities that the state considers 'fringe' or disruptive in some sense, like graffiti art or street protests. Furthermore, political organizations that the state disapproves of may be barred from qualifying as legitimate organizations.

A final option would be for states to ensure that citizens have fair shares of free time that they can use for any activity of their choosing. ${ }^{9}$ If time is necessary for freedom in the republican sense, as I have suggested, it must be available robustly, as a matter of right. Citizens would not be given free time only at the discretion of the powerful, like their employers. Rather, their access to free time would be entrenched by the state, in the form of laws and norms, as one of the basic liberties necessary for free undominated status. Nevertheless, rather than being a demand of republican justice per se, these allotments of free time would serve an instrumental purpose: a more

9 Here, I leave open how a "fair" share of free time ought to be determined. For a detailed discussion of how we can do this, see Rose (2016: 127-134). 
permissive approach to parceling out time-resources would be more effective in bringing about robust levels of political participation, which can be encouraged in two ways. On a more conventional state-centric view, rather than being forced to do so, citizens could be encouraged to use that time for political participation through "soft", non-coercive measures that have already been advocated by republicans (including subsidies for political activities, civic education, or public campaigns promoting political engagement). On a more radical view, the state is corrupt and should not be trusted to guide the appropriate use of our free time, as it would likely seek to align our behavior with the interests of dominating forces through empty civics or other forms of mainstream ideology. Instead, we can carve out a major role for counterpublics, or counter-dominating institutions, to educate and guide us in our resistance to domination..$^{10} \mathrm{I}$ deliberately leave open the question of who the main political influencer over our free time ought to be, to show that this policy can be appealing to different varieties of republicanism. Either way, the guarantee of free time would be likely to encourage political activity amongst citizens in the long run, while avoiding the shortfalls of compulsory political engagement or conditional timeshares. Of course, there is a good chance that most citizens would always prefer to use that time to pursue their own goals or projects, shunning political activity altogether. But I think that the objections to the other policies considered above are sufficiently serious for republicans to bite the bullet.

\section{CONCLUSION}

In this article, I have sought to make a rather bare-bones argument about how republicans can make a case for fair shares of free time, albeit an instrumental one. I pointed out that time is necessary for the creation and maintenance of non-dominating institutions, because we need sufficient time to effectively participate in processes of justification and contestation. I went on to suggest that, while this only entitles individuals to sufficient shares of time dedicated to these forms of political engagement in theory, fair shares of free time may be instrumentally necessary to encourage participation in republican activities.

I have not said anything about what, exactly, constitutes a fair share of free time or how to measure the amount of time that would minimally be required for healthy civic engagement. Neither have I made any policy suggestions for how fair shares of free time can be achieved, a task which

10 For a parallel case of a dominating agent encouraging political participation by those it dominates in order to further its own agenda, see Hertel-Fernandez (2016). 
Rose helpfully takes up in her book. I also do not claim that this route is the only one available to republicans for justifying fair shares of free time; there may be other, perhaps even more convincing, ways of linking nondomination to free time. These remaining questions provide fertile ground for future discussion. Nevertheless, I hope that my contribution takes an important first step in considering a potential republican justification for the entitlement to free time.

\section{BIBLIOGRAPHY}

Anderson, E., 2015: Private Government, Princeton: Princeton University Press.

Bellamy, R., 2008: "Republicanism, Democracy, and Constitutionalism", Republicanism and Political Theory, eds. C. Laborde and J. Maynor, 159-189, Chichester: Blackwell Publishing Ltd.

Benton, M., 2010: "The Tyranny of the Enfranchised Majority? The Accountability of States to their Non-Citizen Population", Res Publica 16: 397-413.

Borman, D., 2017: “Contractualism and the Right to Strike”, Res Publica 23: 81-98.

Compa, L., 2004: Blood, Sweat and Fear, Human Rights Watch.

Gourevitch, A., 2013: "Labor republicanism and the transformation of work", Political Theory 41: 591-167.

- 2015: “Quitting work but not the job: liberty and the right to strike”, Perspectives on Politics 14: 307-323.

- 2016: "The Limits of a Basic Income: Means and Ends of Workplace Democracy", Basic Income Studies 11: 17-28.

Hertel-Fernandez, A., 2016: "How Employers Recruit Their Workers into Politics And Why Political Scientists Should Care", Perspectives on Politics 14: 410-421.

Hsieh, N., 2007: "Survey Article: Justice in Production", The Journal of Political Philosophy 16: 72-100.

Jordan, B., 2017: "Graduate Students on These 7 Campuses Are Fighting for Their Labor Rights", The Nation.

Lovett, F., 2013: A General Theory of Domination and Justice, Oxford: Oxford University Press.

Pettit, P., 1997: Republicanism, Oxford: Oxford University Press.

Rivlin-Nadler, M., 2017: “Trump the Union-Buster”, New Republic.

Rose, J., 2017: Free Time, Princeton: Princeton University Press.

Semuels, A., 2017: "Will Grad Students Lose the Right to Unionize Under Trump?", The Atlantic. 